\title{
The importance of coronary artery disease and special considerations for left ventricular assist device implantation
}

\author{
Mevlüt Çelik ${ }^{1}$, John M. Stulak², Simon Maltais ${ }^{3}$ \\ ${ }^{1}$ Department of Cardiothoracic Surgery, Erasmus University Medical Center, Rotterdam, The Netherlands; ${ }^{2}$ Department of Cardiovascular Surgery, \\ Mayo Clinic College of Medicine and Sciences, Rochester, MN, USA; ${ }^{3}$ Department of Cardiovascular Surgery, Cardiovascular Institute of Los \\ Robles Hospital and Medical Center, Hospital Corporation of America, Thousand Oaks, CA, USA \\ Correspondence to: Simon Maltais, MD, PhD. Department of Cardiovascular Surgery, Cardiovascular Institute of Los Robles Hospital and Medical \\ Center, Hospital Corporation of America, 227 West Janss Rd, Thousand Oaks, CA 91360, USA. Email: SimonMaltais@mac.com.
}

Submitted Nov 25, 2020. Accepted for publication Feb 15, 2021.

doi: 10.21037/acs-2020-cfmcs-31

View this article at: http://dx.doi.org/10.21037/acs-2020-cfmcs-31

Congestive heart failure (CHF) is one of the leading global healthcare problems, with an estimated worldwide prevalence of twenty-five million people (1). The shortage of healthy donor hearts gives rise to the need for alternative treatment options. Left ventricular assist devices (LVADs) have shown excellent outcomes in patients with CHF (2) and in those bridged for heart transplantations (3). LVAD is seen as a cornerstone of surgical treatment for patients with advanced heart failure, currently exceeding that of annual heart transplantations (4). Acute myocardial infarction (MI) and chronic ischemic cardiomyopathy are major indications for LVAD implantation. Persistent coronary artery disease (CAD) is typically not addressed during LVAD implantation, and yet it remains an important adverse risk to be considered after LVAD implantation.

In patients with preoperative ischemic cardiomyopathy and CAD-related risk factors, there is very low incidence of clinically relevant events and subsequent interventions. Adverse events during and after LVAD implantation are the "Achilles heel" of an otherwise highly successful procedure. Yet, the increase in combined surgery with subsequent increased risk of adverse events is duly noted. Combined surgery, including aortic, mitral and tricuspid valve surgery have become common, with incidence risen up to $35 \%$, especially to prevent post-LVAD adverse events (5). Likewise, concomitant coronary artery bypass grafting (CABG) can also be performed to prevent postLVAD events, yet the benefit of concomitant CABG has been questioned (6). LVAD with concomitant CABG was associated with a decreased survival, while no reduction in early right ventricular (RV) failure was noted. In specific patients with preoperative severe RV dysfunction, concomitant CABG may yield benefit. Currently, a high incidence of early RV failure and early ventricular arrhythmias (up to $25 \%$ ) are seen after LVAD implantation (7). Optimal coronary artery flow has been argued to reduce postoperative adverse events due to the positive impact on RV function.

Patients with severe ischemic cardiomyopathy (left ventricular function $\leq 30 \%$ ) are also prone to developing severe ischemic mitral regurgitation. CABG with concomitant mitral repair has been the standard treatment in those patients with a 5 -year survival of $51 \%(8)$. Nevertheless, a paradigm shift in the use of long-term mechanical support devices has led to the increase of LVAD use as destination therapy in patients with endstage ischemic cardiomyopathy due to the unavailability of coronary targets or non-viability of the myocardium, with similar acceptable outcomes (9). LVAD is an effective treatment strategy if performed promptly and should always be considered early for patients with MI and severe left ventricular dysfunction. The coronary endothelial function does not worsen by long-term LVAD support and is in fact, improved.

Whether increased coronary blood flow due to CABG would reduce postoperative complications remains unanswered. While the risk factors and mechanisms of RV failure (RVF) are multifactorial, mostly attributed to changes in RV preload, RV afterload and RV contractility (10), concomitant CABG with LVAD increases cardiopulmonary 
bypass time. Prolonged cardiopulmonary bypass duration has been independently associated with prolonged cardiac stunning and subsequently, increased post-operative morbidity and mortality in LVAD as well as cardiac surgery (10).

\section{Special considerations}

We believe there are special situations that merit discussion and thorough evaluation during the pre-operative phase. In patients with recent stent placement, it is critical to maintain a consensus on the management of peri-operative antiplatelet agents, a therapy-guided use of blood products, an avoidance of hypotension, and an increased awareness of risk of postsurgical coronary re-stenosis. Several of these factors alone or in combination can lead to early post-operative coronary complications. Postoperative RV failure or refractory arrhythmia can be related not only to LVAD placement, but also with coronary re-stenosis. The development of acute RV dysfunction and recurrent ventricular ectopy has been associated with early stent restenosis. Early coronary angiogram and percutaneous reopening of the right coronary artery however, normalizes $\mathrm{RV}$ function and resolves ventricular arrhythmias.

In patients with previous coronary artery bypasses, it is critical to obtain a recent coronary angiogram to evaluate coronary anatomy prior to re-entry, but also to ascertain the topography of right-system coronary circulation. Patients with ischemic heart disease can be dependent on bypasses for right coronary circulation. The left internal mammary graft can potentially be the only source for collateralization to a large right-sided system. Injuries to the graft by sternal re-entry or amputation of distal left anterior descending artery (LAD) by apical placement of the LVAD can result in acute RV failure. A subsequent loss of RV perfusion from collateral flow amputation can result in peri-operative adverse outcomes. In these cases, ensuring the LVAD placement is kept safely away from the LAD becomes critical. A prophylactic graft to the right coronary artery or alternative placement using left thoracotomy anterolateral placement could help protect coronary perfusion.

CAD can present with acute MI complicated by left ventricular dysfunction ( $\mathrm{LVEF} \leq 30 \%$ ). Although, with early revascularization, LVAD implantation should be considered. The timing of LVAD implantation to prevent cardiogenic shock remains a topic of debate, yet early unloading of the infarcted myocardium has improved overall outcomes in patients who do not respond to medical therapy (11). Acute
MI can lead to the development of left ventricular aneurysm and conveys risk for adverse events (such as ventricular arrhythmias, thromboembolism, and even rupture). Left ventricular aneurysmectomy during LVAD implantation is indicated when there is (I) a thin scar wall of the aneurysm predicted to cause subsequent hemodynamic disturbances, and (II) clot formation in the aneurysmal sac. Therefore, LVAD implantation can be combined with concomitant modified endoventricular circuloplasty (the Dor procedure). The left ventricular aneurysmal sac is opened, thrombotic material is removed, and the transition zone between the scar and viable myocardial muscle is identified. Two pursestring 2-0 Prolene sutures are placed circumferentially at the transition zone and tied after the LVAD pump is secured to the ring to compensate for eventual size discrepancy between the pump and left ventricular opening. The apical ring of the LVAD is then sutured with multiple circumferential pledgeted sutures (12).

LVAD remains an effective treatment strategy and should be considered in patients with CAD and left ventricular dysfunction. Vigilance for unexpected complications in patients with previous CAD and with previous revascularization should be maintained.

\section{Acknowledgments}

Funding: None.

\section{Footnote}

Conflicts of Interest: The authors have no conflicts of interest to declare.

Open Access Statement: This is an Open Access article distributed in accordance with the Creative Commons Attribution-NonCommercial-NoDerivs 4.0 International License (CC BY-NC-ND 4.0), which permits the noncommercial replication and distribution of the article with the strict proviso that no changes or edits are made and the original work is properly cited (including links to both the formal publication through the relevant DOI and the license). See: https://creativecommons.org/licenses/by-nc-nd/4.0/.

\section{References}

1. Savarese G, Lund LH. Global Public Health Burden of Heart Failure. Card Fail Rev 2017;3:7-11.

2. Slaughter MS, Rogers JG, Milano CA, et al. Advanced 
heart failure treated with continuous-flow left ventricular assist device. N Engl J Med 2009;361:2241-51.

3. Stehlik J, Hosenpud JD, Edwards LB, et al.

ISHLT International Registry for Heart and Lung Transplantation--into the fourth decade, from strength to strength. J Heart Lung Transplant 2013;32:941-50.

4. Wever-Pinzon O, Drakos SG, Kfoury AG, et al. Morbidity and mortality in heart transplant candidates supported with mechanical circulatory support: is reappraisal of the current United network for organ sharing thoracic organ allocation policy justified? Circulation 2013;127:452-62.

5. Rogers JG, Pagani FD, Tatooles AJ, et al. Intrapericardial Left Ventricular Assist Device for Advanced Heart Failure. N Engl J Med 2017;376:451-60.

6. Mehta P, Imamura T, Juricek C, et al. Combined Left Ventricular Assist Device and Coronary Artery Bypass Grafting Surgery: Should We Bypass the Bypass? ASAIO J 2020;66:32-7.

7. Garan AR, Yuzefpolskaya M, Colombo PC, et al. Ventricular arrhythmias and implantable cardioverterdefibrillator therapy in patients with continuous-flow left ventricular assist devices: need for primary prevention? J

Cite this article as: Çelik M, Stulak JM, Maltais S. The importance of coronary artery disease and special considerations for left ventricular assist device implantation. Ann Cardiothorac Surg 2021;10(2):268-270. doi:10.21037/acs-2020-cfmcs-31
Am Coll Cardiol 2013;61:2542-50.

8. Ngaage DL, Daly RC, Rosales G, et al. Mitral regurgitation surgery in heart failure due to ischemic cardiomyopathy: a 24-year experience. J Heart Valve Dis 2008;17:251-9; discussion 259-60.

9. Maltais S, Tchantchaleishvili V, Schaff HV, et al. Management of severe ischemic cardiomyopathy: left ventricular assist device as destination therapy versus conventional bypass and mitral valve surgery. J Thorac Cardiovasc Surg 2014;147:1246-50.

10. Salis S, Mazzanti VV, Merli G, et al. Cardiopulmonary bypass duration is an independent predictor of morbidity and mortality after cardiac surgery. J Cardiothorac Vasc Anesth 2008;22:814-22.

11. Acharya D, Loyaga-Rendon RY, Pamboukian SV, et al. Ventricular Assist Device in Acute Myocardial Infarction. J Am Coll Cardiol 2016;67:1871-80.

12. Chamogeorgakis T, Kostopanagiotou K, Behler A, et al. HeartMate 3 left ventricular assist device implant after excision of a large apical aneurysm. Proc (Bayl Univ Med Cent) 2020;33:455-6. 